\title{
Sistem Informasi Manajemen Try Out CBT (Computer Based Test) Untuk Sekolah Menengah Pertama
}

\author{
Muhammad Asri Safi'ie *, Galih Agung Prabawa \\ Program Studi D3 Teknik Informatika, Universitas Sebelas Maret \\ Email: safiie99@staff.uns.ac.id*, galihagung@student.uns.ac.id
}

\section{Info Artikel}

Kata Kunci :

UNBK, CBT, ujian nasional

\section{Keywords :}

computer based test, final exam

Tanggal Artikel

Dikirim : 29 Oktober 2020

Diterima : 30 Mei 2021

\begin{abstract}
Abstrak
Ujian nasioanal merupakan satu agenda penting dalam pelaksanaan proses pendidikan formal di Indonesia. Ujian nasional menjadi penilaian akhir proses belajar seseorang dalam jenjang pendidikan di sekolah. Dari masa ke masa, Ujian nasional mengalami banyak perubahan dalam hal pelaksanaannya. Di era kepemimpinan Mendikbud Anies Baswedan, mulai dicanangkan sistem Ujian Nasional Berbasis Komputer (UNBK) atau yang lebih dikenal sebagai CBT (Computer Based Test). Seiring dengan peningkatan fasilitas komputer di sekolah-sekolah sistem ini perlahan-lahan akan menggantikan sistem ujian nasional yang selama ini dilakukan menggunakan kertas (Paper Based Test). Namun perkembangan ini tidak disertai dengan perkembangan kemampuan sekolah sebagai pelaksana UNBK untuk memberikan fasilitas latihan bagi para siswanya guna menghadapi UNBK. Pemerintah pusat memang tidak menyiapkan fasilitas secara khusus bagi sekolah untuk melaksanakan try out UNBK. Disamping itu penggunaan sistem UNBK yang harus dikoordinir dari pusat tidak memngkunkan bagi sekolah untuk menggunaknnya secara mandiri. Maka dari itu jika pihak sekolah ingin melaksanakan try out UNBK, pihak sekolah harus mengadakannya secara mandiri menggunakan sistem lain yang penggunaannya cukup dengan perangkat komputer yang ada di sekolah. Aplikasi dikembangkan dengan metode waterfall dan dibuat dengan bahasa pemrograman PHP database SQL. Hasil penelitian menunjukkan aplikasi mampu diajalankan perangkat komputer yang ada di sekolah dan memberikan manfaat lain bagi para guru agar bisa menilai kesiapan para siswanya dalam menghadapi UNBK.
\end{abstract}

\begin{abstract}
The national exam is an important agenda in the implementation of the formal education process in Indonesia. The national exam is the final assessment of a person's learning process at the level of education at school. From time to time, the National Examination has undergone many changes in terms of its implementation. In the era of the leadership of Minister of Education and Culture Anies Baswedan, the Ujian Nasional Berbasis Komputer (UNBK) system or better known as CBT (Computer Based Test) was launched. Along with the improvement of computer facilities in schools, this system will slowly replace the national examination system which has been conducted using paper (Paper Based Test). However, this development is not accompanied by the development of the ability of schools as UNBK implementers to provide training facilities for their students to face UNBK. The central government did not prepare special facilities for schools to carry out the UNBK try out. In addition, the use of the UNBK system which must be coordinated from the center does not allow schools to use it independently. Therefore, if the school wants to carry out the UNBK try out, the school must conduct it independently using another system whose use is sufficient with computer equipment at the school. The application was developed using the waterfall method and made using the PHP SQL database programming language. The results showed that the application was able to run on computer devices in schools and provided other benefits for teachers so that they could assess the readiness of their students to face the UNBK.
\end{abstract}




\section{PENDAHULUAN}

Proses pendidikan dasar dan menengah di Indonesia menjadikan ujian nasional sebagai salah satu parameter penting dalam menilai prestasi belajar para siswa [2][4]. Dari masa ke masa, mekanisme ujian nasional mengalami banyak perubahan dari segi metode pelaksanaan, penilaian hasil, dsb. Pada awalnya ujian nasional dilaksanakan dengan memberikan soal berbentuk essay kepada siswa. Seiring berjalannya waktu mekanisme tersebut dirubah dengan menerapkan soal ujian berbentuk pilihan ganda dengan format LJK (Lembar Jawab Komputer) yang mana lembar hasil ujian para siswa bisa dikoreksi secara terkomputerisasi. Semenjak tahun 2014 diterapkan mekanisme ujian nasional berbasis komputer atau UNBK (Ujian Nasional Berbasis Komputer) dimana dengan menerapkan UNBK, siswa akan melakukan ujian nasional secara online melalui komputer yang ada sekolah [3]. Namun dikarenakan sarana yang memadai untuk melaksanakan UNBK belum tentu dimiliki oleh setiap sekolah yang ada di Indonesia maka UNBK hanya dilaksanakan di sekolah tertentu saja dan beberapa sekolah ada yang melaksanakan UNBK dengan meminjam sarana yang ada di sekolah lain.

Mengingat sarana pelaksanaan UNBK yang terbilang cukup mahal, sangat disayangkan jika sarana tersebut hanya digunakan sekali saja dalam satu tahun [5]. Oleh karena itu agar bisa mengoptimalkan sarana yag ada, pihak sekolah pada umumnya melaksanakan latihan UNBK secara mandiri. Akan tetapi aplikasi UNBK hanya bisa berjalan dengan koordinasi dari pemerintah pusat dengan kata lain aplikasi UNBK tidak bisa digunakan oleh pihak sekolah secara mandiri jadi pihak sekolah perlu mengadakan aplikasi sendiri untuk melaksanakan latihan UNBK. Aplikasi tersebut harus mampu mewakili kemampuan dasar yang dimiliki aplikasi UNBK dan mampu menjadi media monitoring perkembangan belajar para siswa sehingga membantu pihak sekolah dalam menentukan kebijakan selanjutnya.

\section{METODE PENELITIAN}

Penelitian ini menggunakan metode waterfall. Pressman [1] menjelaskan model waterfall adalah model klasik yang bersifat sistematis, berurutan dalam membangun software. Nama model ini sebenarnya adalah "Linear Sequential Model". Model ini sering disebut juga dengan "classic life cycle" atau metode waterfall [6][7][8].

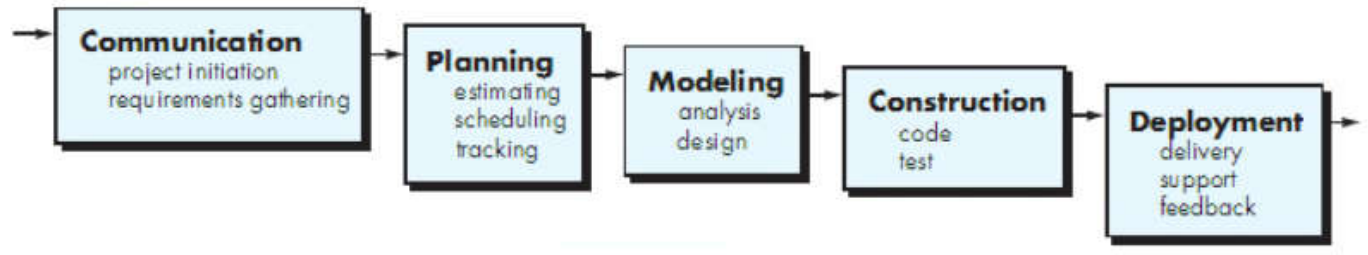

Gambar 1. Metodologi Penelitian Model Waterfall

Berikut adalah penjelasan dari gambar di atas:

1. Communication (Project Initiation \& Requirements Gathering)

Sebelum memulai pekerjaan yang bersifat teknis, sangat diperlukan adanya komunikasi dengan calon user demi memahami dan mencapai tujuan yang ingin dicapai [1]. Hasil dari komunikasi tersebut adalah inisialisasi proyek, seperti menganalisis permasalahan yang dihadapi dan mengumpulkan data-data yang diperlukan, serta membantu mendefinisikan fitur dan fungsi software.

2. Planning (Estimating, Scheduling, Tracking)

Selanjutnya adalah tahapan perencanaan yang menjelaskan tentang estimasi tugas-tugas teknis yang akan dilakukan, resiko-resiko yang dapat terjadi, sumber daya yang diperlukan dalam membuat sistem, produk kerja yang ingin dihasilkan, penjadwalan kerja yang akan dilaksanakan, dan tracking proses pengerjaan sistem.

3.Modeling (Analysis \& Design)

Tahapan ini adalah tahap perancangan dan pemodelan arsitektur sistem yang berfokus pada perancangan struktur data, arsitektur software, tampilan interface, dan algoritma program. Tujuannya untuk lebih memahami gambaran besar dari apa yang akan dikerjakan.

4. Construction (Code \& Test) 
Tahapan Construction ini merupakan proses penerjemahan bentuk desain menjadi kode atau bentuk/bahasa yang dapat dibaca oleh mesin. Setelah pengkodean selesai, dilakukan pengujian terhadap sistem dan juga kode yang sudah dibuat. Tujuannya untuk menemukan kesalahan yang mungkin terjadi untuk nantinya diperbaiki.

5. Deployment (Delivery, Support, Feedback)

Tahapan Deployment merupakan tahapan implementasi software ke customer, pemeliharaan software secara berkala, perbaikan software, evaluasi software, dan pengembangan software berdasarkan umpan balik yang diberikan agar sistem dapat tetap berjalan dan berkembang sesuai dengan fungsinya [1].

\section{HASIL DAN PEMBAHASAN}

\subsection{Deskripsi Umum}

Aplikasi try out UNBK diciptakan dengan bahasa pemrograman PHP dengan memanfaatkan framework Codeigniter, hal ini bertujuan untuk kemudahan pengembangan sistem dan pemanfaatan insfrastruktur yang sama dengan UNBK yang sesungguhnya. Penggunakan aplikasi try out UNBK melibatkan tiga jenis user yaitu admin sebagai pengelola data dasar yang dibutuhkan untuk pelaksanaan ujian, guru sebagai pihak yang membuat soal ujian dan dapat melihat nilai siswa sesuai mata pelajaran yang diampu serta siswa sebagai user yang melaksanakan ujian.

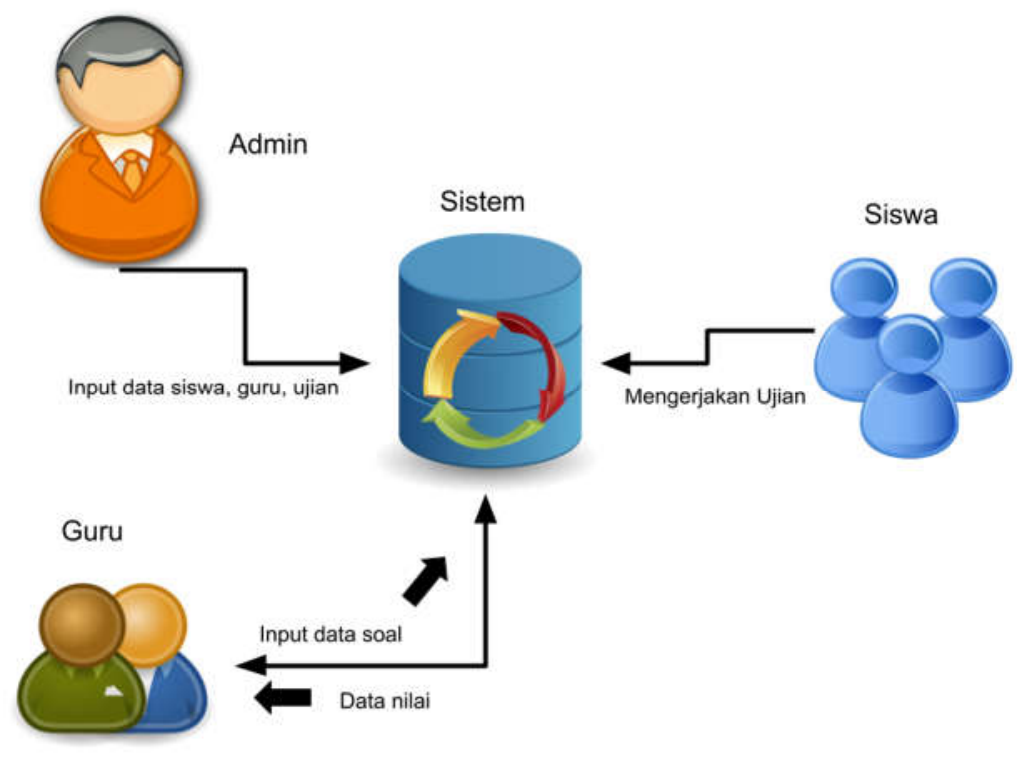

Gambar 2. Proses Bisnis Aplikasi Try Out UNBK

\subsection{Implementasi}

\subsubsection{Class Diagram}

Seperti yang sudah dijelaskan diatas, aplikasi try out UNBK melibatkan tiga jenis user (aktor). Sebelum melaksnakan ujian, admin harus memasukkan data-data pokok yang menjadi dasar pelaksanaan ujian seperti data siswa, data guru, data kelas, data mata pelajan, data kelompok (kloter) ujian dan data jadwal ujian. Setelah itu guru bisa memasukkan soal yang hendak diujikan lalu admin bisa menjadwalkan ujian bagi para siswa. Berikut adalah skema kerja sistem dalam class diagram 


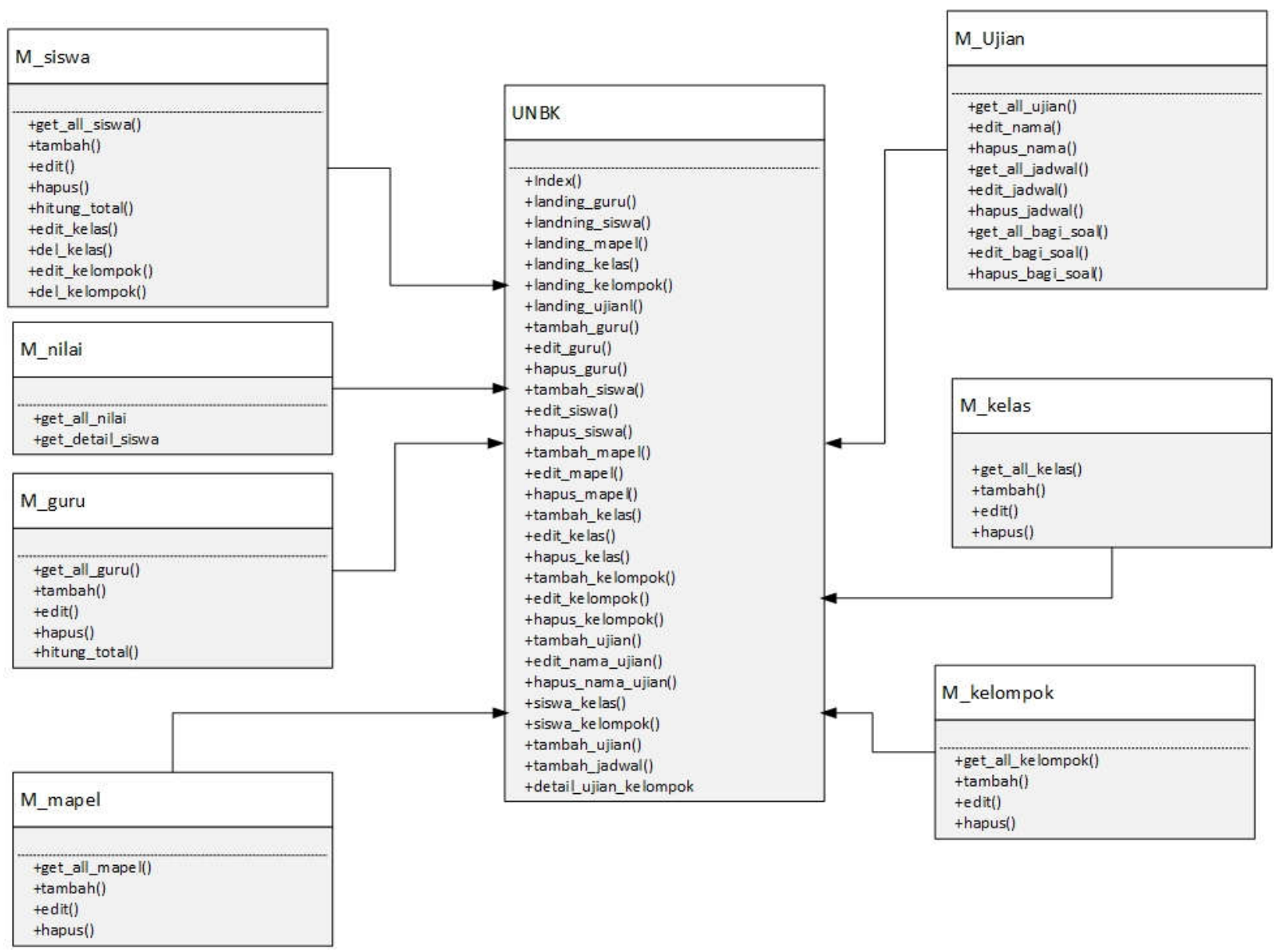

\section{Gambar 3. Class Diagram}

Sistem ini dibangun dengan framework Codeigniter 3 yang mana prinsipkerjanya menggunakan metode MVC (Model, View, Controller) oleh karena itu, terdapat satu class controller yang berfungsi sebagai pusat koordinasi di dalam sistem.dan beberapa class model yang berfungsi untuk pemrosesan database.

\subsubsection{User Interface}

Sistem ini memiliki tiga actor namun kali ini pembahasan terbatas pada dua actor yaitu admin dan guru, bagian actor siswa ada pada pembahasan tersendiri. Berikut rancangan tampilannya pada Gambar 4.

\begin{tabular}{|c|c|c|c|}
\hline Try Out UNBK & & & Admir \\
\hline Dasboard & \multirow{4}{*}{$\begin{array}{l}\text { Data Siswa } \\
200\end{array}$} & \multirow{4}{*}{$\begin{array}{l}\text { Data Guru } \\
\text { C } 20\end{array}$} & \\
\hline Management Dato > & & & \multirow{3}{*}{$\begin{array}{l}\text { Bank Sool } \\
50\end{array}$} \\
\hline -Data Guru & & & \\
\hline -Data Siswa & & & \\
\hline \multicolumn{4}{|l|}{ Mata Pelajoran } \\
\hline \multicolumn{4}{|l|}{ Kelas } \\
\hline \multicolumn{4}{|l|}{ Kelompok Ujian } \\
\hline Ujian & & & \\
\hline
\end{tabular}

(a) 


\begin{tabular}{|c|c|c|c|c|c|c|c|}
\hline \multicolumn{5}{|c|}{ Try Out UNBK } & & \multicolumn{2}{|c|}{ Admin } \\
\hline \begin{tabular}{|l|} 
Dasboard \\
\end{tabular} & \multirow{2}{*}{ 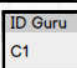 } & \multirow{2}{*}{$\begin{array}{l}\text { Noma } \\
\text { Hona }\end{array}$} & \multirow{2}{*}{$\begin{array}{l}\text { Gender } \\
P\end{array}$} & \multirow{2}{*}{$\begin{array}{l}\text { Username } \\
\text { hana }\end{array}$} & \multirow{2}{*}{\begin{tabular}{|l} 
Password \\
123
\end{tabular}} & \multirow{2}{*}{$\begin{array}{l}\text { Id_mapel } \\
\text { B Ind }\end{array}$} & Jubah \\
\hline Manogement Dato > & & & & & & & Edit hap \\
\hline -Dato Guru & \multirow{3}{*}{$\begin{array}{l}\mathrm{C}_{2} \\
\mathrm{C} 3\end{array}$} & \multirow{2}{*}{$\begin{array}{l}\text { Hani } \\
\text { Doni }\end{array}$} & \multirow{2}{*}{ P } & \multirow{2}{*}{$\begin{array}{l}\text { hani } \\
\text { doni }\end{array}$} & \multirow{2}{*}{456} & $B$ Ing & 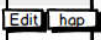 \\
\hline -Data Siswa & & & & & & IPA & Edit hor \\
\hline Mata Pelojaran & & & $I^{2}$ & & & & \\
\hline Kelas & & & & & & & \\
\hline Kelompok Ujian & & & & & & & \\
\hline Ujian & & & & & & & \\
\hline
\end{tabular}

(b)

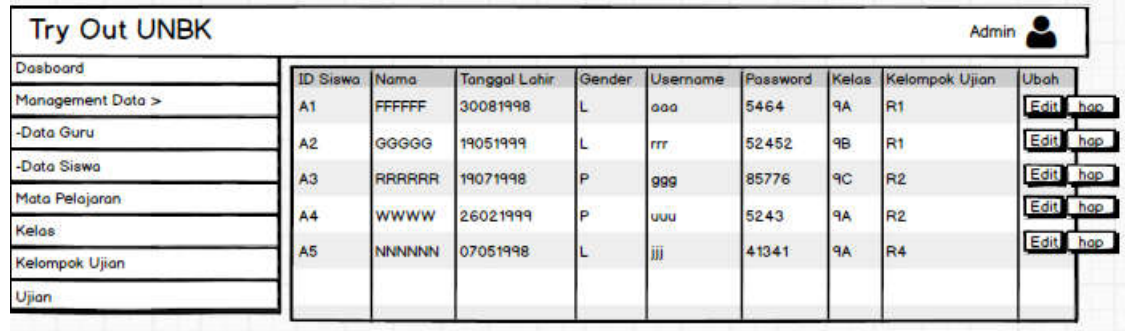

(c)

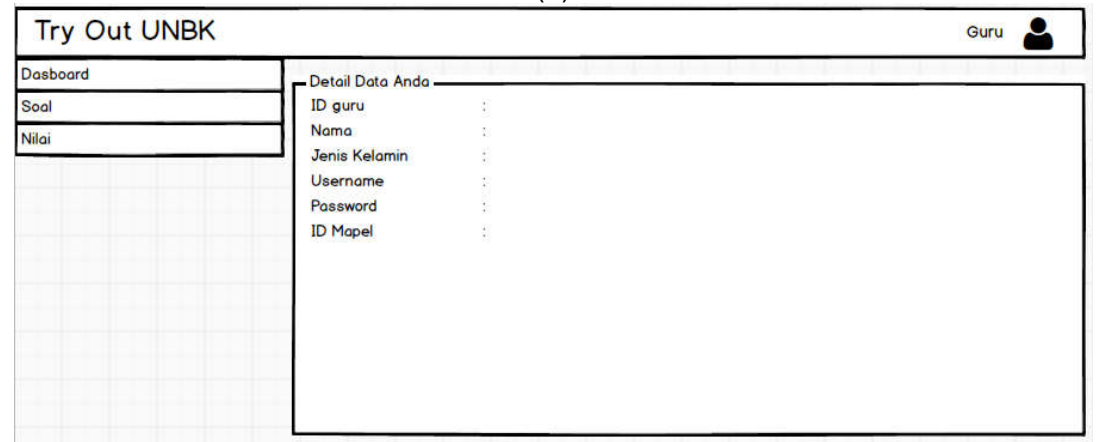

(d)

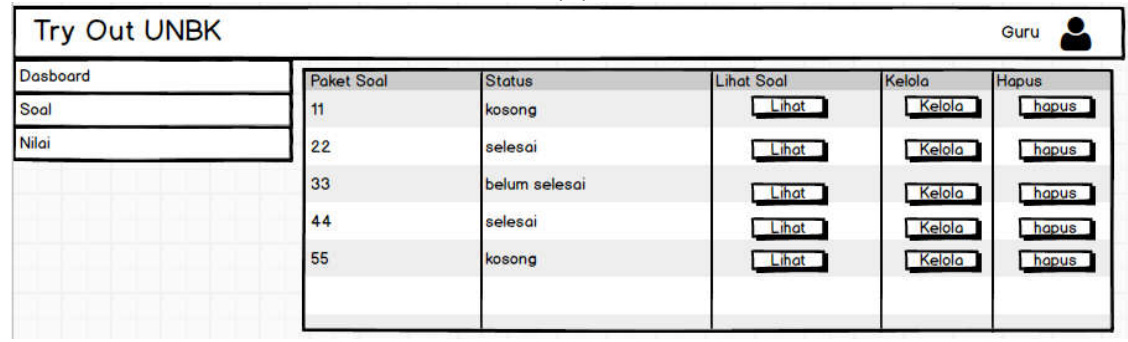

Gambar 4. Rancangan User Interface

Dari rancangan tampilan seperti di atas menghasilkan implementasi tampilan seperti Gambar 5.

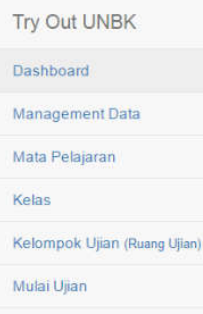

\section{Dashboard}
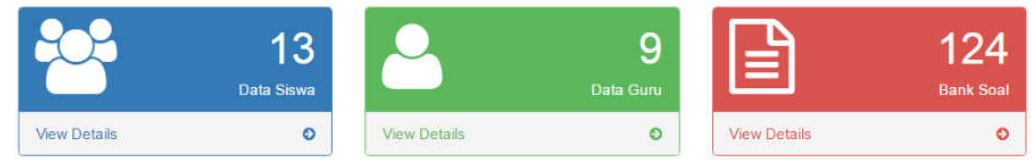

(a) 


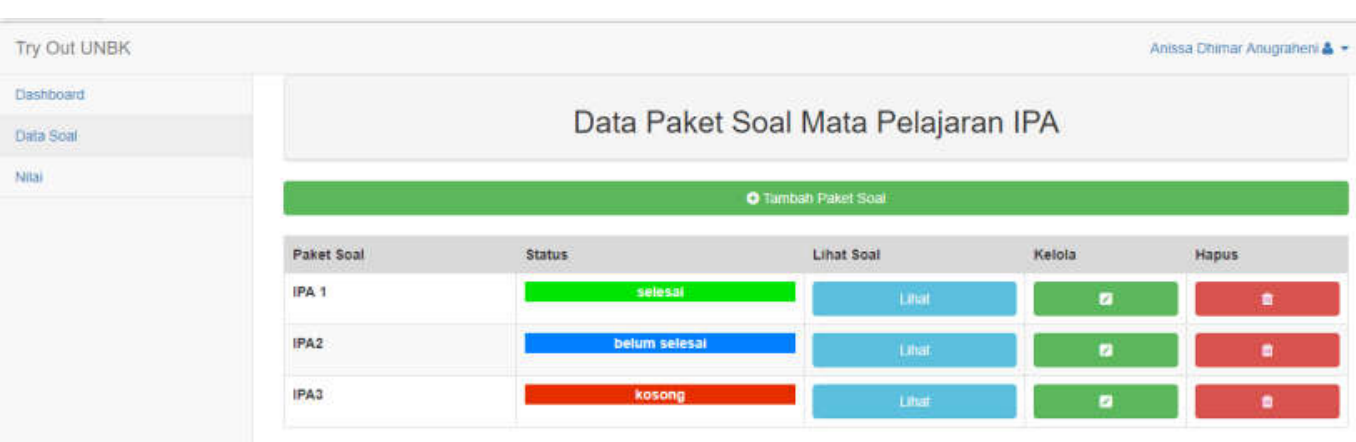

(b)

Gambar 5. Implementasi User Interface

\subsubsection{Pengujian}

Berikut adalah pengujian aplikasi dengan menggunakan metode blackbox dimana pengujian dilakukn dengan memberikan masukan dan melihat apakah aplikasi merespon dengan benar atau tidak. Berikut pengujian yang dijabarkan pada Tabel 1.

Tabel 1. Tabel Pengujian

\begin{tabular}{|c|c|c|c|}
\hline Pengujian & Skenario Uji & Hasil yang diharapkan & Status \\
\hline Tambah data guru & $\begin{array}{l}\text { Admin menjalankan fungsi tambah data } \\
\text { guru }\end{array}$ & $\begin{array}{l}\text { Berhasil menambahkan data } \\
\text { guru }\end{array}$ & Berhasil \\
\hline Edit data guru & Admin merubah data guru yang sudah ada. & Data guru berhasil diubah & Berhasil \\
\hline Hapus data guru & Admin menghapus data guru yang ada & Data guru berhasil dihapus & Berhasil \\
\hline Tambah data siswa & $\begin{array}{l}\text { Admin menjalankan fungsi tambah data } \\
\text { siswa }\end{array}$ & $\begin{array}{l}\text { Berhasil menambahkan data } \\
\text { siswa }\end{array}$ & Berhasil \\
\hline Edit data siswa & $\begin{array}{l}\text { Admin merubah data siswa yang sudah } \\
\text { ada. }\end{array}$ & Data siswa berhasil diubah & Berhasil \\
\hline Hapus data siswa & Admin menghapus data siswa yang ada & Data siswa berhasil dihapus & Berhasil \\
\hline $\begin{array}{l}\text { Tambah data mata } \\
\text { pelajaran }\end{array}$ & $\begin{array}{l}\text { Admin menjalankan fungsi tambah data } \\
\text { mata pelajaran }\end{array}$ & $\begin{array}{l}\text { Berhasil menambahkan data } \\
\text { mata pelajaran }\end{array}$ & Berhasil \\
\hline Edit data mata pelajaran & $\begin{array}{l}\text { Admin merubah data mata pelajaran yang } \\
\text { sudah ada. }\end{array}$ & $\begin{array}{l}\text { Data mata pelajaran berhasil } \\
\text { diubah }\end{array}$ & Berhasil \\
\hline $\begin{array}{l}\text { Hapus data mata } \\
\text { pelajaran }\end{array}$ & $\begin{array}{l}\text { Admin menghapus data mata pelajaran } \\
\text { yang ada }\end{array}$ & $\begin{array}{l}\text { Data mata pelajaran berhasil } \\
\text { dihapus }\end{array}$ & Berhasil \\
\hline Tambah data kelas & Admin menambah kelas & Data kelas berhasil ditambah & Berhasil \\
\hline $\begin{array}{l}\text { Tambah siswa ke dalam } \\
\text { kelas }\end{array}$ & $\begin{array}{l}\text { Admin mengelompokkan siswa berdasrkan } \\
\text { kelas yang sudah dibuat }\end{array}$ & $\begin{array}{l}\text { Keterangan kelas pada data } \\
\text { siswa berhasil dirubah }\end{array}$ & Berhasil \\
\hline Hapus data kelas & Admin menghapus kelas & Data kelas berhasil dihapus & Berhasil \\
\hline $\begin{array}{l}\text { Tambah data kelompok } \\
\text { ujian }\end{array}$ & Admin menambah kelompok ujian & $\begin{array}{l}\text { Data kelompok ujian berhasil } \\
\text { ditambah }\end{array}$ & Berhasil \\
\hline $\begin{array}{l}\text { Tambah siswa ke dalam } \\
\text { kelompok ujian }\end{array}$ & $\begin{array}{l}\text { Admin mengelompokkan siswa berdasrkan } \\
\text { kelompok ujian yang sudah dibuat }\end{array}$ & $\begin{array}{l}\text { Keterangan kelompok ujian } \\
\text { pada data siswa berhasil } \\
\text { dirubah }\end{array}$ & Berhasil \\
\hline $\begin{array}{l}\text { Hapus data kelompok } \\
\text { ujian }\end{array}$ & Admin menghapus kelompok ujian & $\begin{array}{l}\text { Data kelompok ujian berhasil } \\
\text { dihapus }\end{array}$ & Berhasil \\
\hline Membuat jadwal & Admin membuat jadwal Ujian & Jadwal berhasil dibuat & Berhasil \\
\hline
\end{tabular}




\begin{tabular}{llll} 
Membagi Soal & $\begin{array}{l}\text { Admin membagi paket soal untuk siswa } \\
\text { berdasarkan jadwal yang telah dibuat }\end{array}$ & $\begin{array}{l}\text { Soal berhasil dibagi } \\
\text { berdasrakan jadwal }\end{array}$ & Berhasil \\
\hline
\end{tabular}

\section{KESIMPULAN}

Penelitian yang telah dilakukan telah berhasil membuat aplikasi ujian berbasis komputer. Aplikasi ini pada bagian front end yang dihadapi siswa, aplikasi ini memiliki skema yang mirip dengan aplikasi UNBK Kemendikbud. Hal ini berguana sebagai proses pembiasaan siswa terhadap sistem agar nantinya saat para siswa menghadapi ujian yang sesungguhnya tidak lagi merasa asing. Sebagaimana Try Out pada umumnya yang digunakan sekolah untuk mempersiapkan siswa menghadapi ujian, hasil akhir aplikasi ini juga mampu digunakan sebagai parameter kesiapan siswa menghadapi ujian sehingga para guru dapat menentukan langkah pengajaran selanjutnya.

Sistem ini bukanlah system yang sudah sempurna oleh karena itu untuk pengembangan lebih lanjut ada beberapa saran yaitu sistem terbatas untuk latihan siswa SMP sederajat. Untuk kedepannya, sistem ini bisa dikembangkan untuk memenuhi kebutuhan model ujian yang lainnya seperti UNBK untuk SMA dan UKG (Uji Kompetensi Guru)

\section{DAFTAR PUSTAKA}

[1] Pressman, R. 2015. Rekayasa Perangkat Lunak: Pendekatan Praktisi Buku 1. Yogyakarta: ANDI.

[2] Alawiyah, F. 2017. Standar Nasional Pendidikan Dasar Dan Menengah. Aspirasi Vol 8 No 1. PP 82-92

[3] Pakpahan, Rogers. 2016. Model Ujian Nasional Berbasis Komputer: Manfaat Dan Tantangan ComputerBased National Exam Model: Its Benefits And Barriers. Jurnal Pendidikan dan Kebudayaan Vol. 1. PP 19-35

[4] Idrus L. 2019. Evaluasi Dalam Proses Pembelajaran. Adaara:Jurnal Managemen Pendidikan Islam Vol 9 No 2. PP 1-16

[5] Nurdin. 2021. Strategi Kepala Sekolah dalam Pelaksanaan Ujian Nasional Berbasis Komputer (UNBK) di Sekolah Menengah Pertama. Al-Ta'dib Jurnal Kajian IImu Kependidikan Vol 14 No 1. PP 1-13

[6] Parwati, Juliana. 2020. Analisa \& Perancangan Sistem Informasi Pusat Kajian Anggaran Pada Badan Keahlian Dpr-Ri Jakarta Dengan Metode Pieces. JUSIBI Vol 2 No 4. PP 557-569

[7] Hariyanto, Dicky. 2021. Implementasi Metode Waterfall Pada Sistem Informasi Pendaftaran Sekolah Seni Tari Balet Berbasis Website (Studi Kasus: On Point Balet School). Jupiter Vol 13 No 2.

[8] Moch. Khusien Bagaskoro. 2021. Benchmarking Metode Rancang Bangun Waterfall Dan Pemodelan Berbasis Objek. Jurnal Teknologi Informasi Vol 15 No 2. PP 1-9. 